\title{
Contrasting differences in identity and agency between narrative and autopoietic systems
}

\begin{tabular}{|c|c|}
\hline \multicolumn{2}{|c|}{$\begin{array}{l}\text { Author: } \\
\text { Nico Buitendag }{ }^{1}\end{array}$} \\
\hline \multicolumn{2}{|c|}{$\begin{array}{l}\text { Affiliation: } \\
{ }^{1} \text { Department of } \\
\text { Jurisprudence, University of } \\
\text { Pretoria, South Africa }\end{array}$} \\
\hline \multicolumn{2}{|c|}{$\begin{array}{l}\text { Note: } \\
\text { This article represents a } \\
\text { reworked version of aspects } \\
\text { of the LLM dissertation } \\
\text { (University of Pretoria), } \\
\text { entitled 'Rethinking time, } \\
\text { ethics and justice: A } \\
\text { jurisprudential perspective' } \\
\text { with Prof. Karin van Marle } \\
\text { as supervisor. Advocate } \\
\text { Nico Buitendag is a student } \\
\text { at Leiden University, in the } \\
\text { Netherlands. }\end{array}$} \\
\hline \multicolumn{2}{|c|}{$\begin{array}{l}\text { Correspondence to: } \\
\text { Nico Buitendag }\end{array}$} \\
\hline \multicolumn{2}{|c|}{$\begin{array}{l}\text { Email: } \\
\text { nbuitendag@gmail.com }\end{array}$} \\
\hline \multicolumn{2}{|c|}{$\begin{array}{l}\text { Postal address: } \\
7 \text { Hugo de Grootstraat } \\
32,2311 X K \text { Leiden, the } \\
\text { Netherlands }\end{array}$} \\
\hline \multicolumn{2}{|c|}{$\begin{array}{l}\text { Dates: } \\
\text { Received: } 27 \text { Mar. } 2013 \\
\text { Accepted: } 26 \text { Apr. } 2013 \\
\text { Published: } 09 \text { July } 2013\end{array}$} \\
\hline \multicolumn{2}{|c|}{$\begin{array}{l}\text { How to cite this article: } \\
\text { Buitendag, N., 2013, } \\
\text { 'Contrasting differences in } \\
\text { identity and agency between } \\
\text { narrative and autopoietic } \\
\text { systems', HTS Teologiese } \\
\text { Studies/Theological Studies } \\
69(1), \text { Art. \#1966, } 7 \text { pages. } \\
\text { http://dx.doi.org/10.4102/ } \\
\text { hts.v69i1.1966 }\end{array}$} \\
\hline \multicolumn{2}{|c|}{$\begin{array}{l}\text { Copyright: } \\
\text { (C) 2013. The Authors. } \\
\text { Licensee: AOSIS } \\
\text { OpenJournals. This work } \\
\text { is licensed under the } \\
\text { Creative Commons } \\
\text { Attribution License. }\end{array}$} \\
\hline \multicolumn{2}{|l|}{ Read online: } \\
\hline 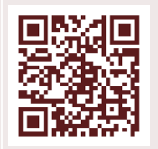 & $\begin{array}{l}\text { Scan this QR } \\
\text { code with your } \\
\text { smart phone or } \\
\text { mobile device } \\
\text { to read online. }\end{array}$ \\
\hline
\end{tabular}

The article aims at contrasting the autopoietic understanding of an individual and her or his actions as described by Niklas Luhmann with Paul Ricoeur's notion of narrative identity, focusing on people as legal subjects. The article assumes that when legal subjects necessitate ethical engagement and evaluation, the law could cease to deal with problems in a mere legalistic fashion but is allowed the freedom to appeal to norms of justice external to itself as in other natural law theories. Through narrative identity the deeds of role players are to be understood in greater complexity than what a self-referential legal system is comfortable in dealing with.

\section{Introduction}

During the last few decades the description of autopoietic systems by Niklas Luhmann has become an important and influential model for how we think about law. Whilst it remains a marvellously meticulous description and abstract conceptualisation of the workings of a legal system, its logic has certain consequences that do not sit well; it is a conservative and positivistic description. Law described as such becomes able to protect itself from the challenge set by justice. By presenting a lacking description of human identity and action, these aspects cannot be fully understood or ethically judged.

In order to evade this responsibility, law has developed methods to logically justify its disengagement with reality. The first of these is through self-definition exercised through boundary drawing. If law has the final say on what it is and is not, it can externalise any norm that poses a threat to it. This boundary acts as a filter of external complexity, allowing such data to have new kinds of legal complexity added to it. This causes a double removal from reality of such data. Through such autopoiesis law is able to regenerate itself whilst ignoring the call for justice.

This mode of law fails particularly when it needs to deal with its subjects. Human beings and their actions have inherently ethical dimensions. Law attaches legal designations in order to make sense of its subjects and their deeds, pulling it further away from its original context and meaning. Humans and their actions are portrayed as being in the service of autopoietic systems, rather than the other way around.

In this article the autopoietic understanding of the individual and his actions as described by Luhmann are contrasted with Paul Ricoeur's point of view on the subject. Through narrative identity the deeds of role players can be understood in greater complexity than what a selfreferential legal system is comfortable in dealing with. When legal subjects are understood in a framework that necessitates ethical engagement and evaluation, law could cease to deal with problems in a mere legalistic fashion and is allowed the freedom to appeal to norms of justice external to itself as in other natural law theories.

\section{Identity}

The way in which a Luhmannian description of the legal system deals with human identity is problematic. Identity is seen in a reductive manner, disempowering the potential of human beings to not only affect change, and even more importantly, of reducing humans to a level where their existence does not demand the law to deal with them wholly or justly.

Systems theory is based on the premise that society is not fundamentally human, but at best (and only in part) a collection of humans (Moeller 2006:5). This is a break from earlier anthropocentric descriptions of society. Society is regarded as the interaction within and between a myriad of systems. When a person buys something, votes in an election, or watches the television news, it is not considered by systems theory as human communication but as economic, political or media communication. This underlies one of the most basic and discouraging premises of systems 
theory: ' $[H]$ uman beings do not and cannot communicate only communication can' (Moeller 2006:9; Luhmann 2008:73). Society ceases to be understood in terms of its members but rather in terms of its events. Humans are regarded as an important external sine qua non to communication, but are not essential to the internal element of communication, holding that we cannot connect to other human beings but only to their communication (Moeller 2006:9; Luhmann 2008:73). Law is also a social system of communication, together with other important systems in its environment.

For Luhmann human beings are made up of many different systems, namely the system of the body (a biological system), mind (a psychic system), as well as various different communicative systems. Whilst individuality lies in the psychic system, it is not seen as enjoying any sort of primacy above the rest as in much of traditional philosophy. There is, in fact, no hierarchy regarding these systems (Moeller 2006:10). A person can be divided into a body, a mind or communicator, and cannot theoretically be regarded as a unified human being (Moeller 2006:10). This concept denies the complex nature of a person.

The systems of mind and society are dependent on one another (structurally coupled). With the assistance of language and communication they have co-evolved a relationship that leads to a certain understanding of human individuality. Individuality and identity are comprised of a combination of psychic and social systems, and express themselves in both these spheres (Moeller 2006:83). In the psychic system identity comes to fruition through self-socialisation. In social systems the individuality of persons - as part of society - is an important self-description of society's own idea of itself. Technically speaking, both systems make their complexity available for the construction of the other (Moeller 2006:83). As much as each mind is its own system, it is informed by the social and cultural information that is available. At the same time, however, social or communicative systems have developed the concept of a person or individual in order to establish parties involved in communication. Social systems need to classify persons as such in order to bestow upon them roles and expectations (such as a 'mother' or an 'accused'). Such individuality bestowed upon a person is highly variable, depending on the system in question, the circumstances and time. Such labels are thus specific semantic designations reflecting certain structural conditions in a society at a specific point in time (Moeller 2006:85; Luhmann 2008:74). Individuality is thus not considered a substantial quality of human existence, but simply a product of the language of psychic and social systems. Luhmann states that there is no object that corresponds with the term 'human being', and that words such as 'person' or 'agent' are simply specific roles taken up within communication (Luhmann 2008:84; Moeller 2006:85).

Luhmann has a problem with constructing human beings as wholly realised and unique. For him granting everyone some kind of uniqueness makes it by its very definition nonunique. He argues that such uniqueness is still determined by society. The terms in which individuality is described is still one of being or not being certain things, for even in saying you are not something you are still orienting yourself in relation to that very thing. This is typical of the binary logic in which Luhmann likes to think: you either are something or not, and nothing in between. This is further problematised by the fact that in social engagements one assumes different personas, or at least different aspects of oneself through division (Moeller 2006:89). One becomes an individual through engaging in social systems.

Another point Luhmann makes is that in pre-modern times identity was at least partly made up of difference and exclusion. Moeller (2006:93) uses the example of the ancient Greeks, who differentiated between themselves and barbarians, a term that denoted 'everyone else'. In contemporary society this is no longer true. Subjectivity requires that nothing can be excluded and all of humanity is neutral to difference. Moeller (2006:89) then asks the question: 'What am I if we are all Greeks?' Human identity is not seen as a complex narrative where each individual has their own history and motivations and goals. If I am not a barbarian, I am a Greek. Luhmann problematises this with what he calls the difference-neutrality of the human rights discourse ultimate freedom of making one's own choices, of no right or wrong way, and the disregard for factual difference - as the 'true' fundamentalism of our time. He describes universal subjectivity and human dignity as meaningless (Luhmann 2008:483; Moeller 2006:94). The ultimate meaning of systems theory is that any difference or inequality can only be applied to a subject by the system itself. It is true that law only recognises the difference that it imparts itself, but is this not true for all discriminatory operations of law? Instead of laying the blame at the feet of the human rights discourse, I contend that this is no different from all the other binary decisions and designations that the law makes. This is the unavoidable expression of autopoiesis, a symptomatic problem that law should resolve. But unlike Luhmann we should not blame the 'fundamentalism' of the human rights discourse, rather the operative closure of law itself. The main point of arguing for narrative identity is in order to open law to particularities and designations prior to itself and its designations.

Autopoiesis becomes the foundation of action and cognition (Moeller 2006:94). Identity and agency is removed from human beings, denying their narrative identity and their right to fulfil their narratives justly. Again we witness the unwillingness of the law to deal with humans as persons with a past and a future, with projects, goals, motivations and ambitions. When identity becomes neutralised in this manner, it becomes impossible to make ethical or just judgements. Identity is reduced to a legally communicated identity that becomes removed and immune to anything outside of legal logic.

Ricoeur, on the other hand, presents a conception of identity ${ }^{1}$ that shows an individual having not only autonomy prior 1.Ricoeur develops his notion of narrative identity in Time and narrative (Ricoeur 1984, 1986, 1988) and Oneself as another (Ricoeur 1992). 
to his own actions or communications but also being intrinsically made up of his own (and others') narrative and its location within time. As MacIntyre (2007) put it:

man is in his actions and practice, as well as in his fictions, essentially a story-telling animal. That means I can only answer the question 'what am I to do' if I can answer the prior question of 'what story or stories do I find myself a part?' (p. 216)

Just like language - symbol and metaphor - narrative is inseparable from the concept of human community (Dowling 2011:37). Moreover, the Other is only made understandable through an analogy to the self, whose narrative impacts on all spheres. Ricoeur discusses the narrative on three levels, namely those of the personal, the political and the ethical.

Law's answers to questions of legitimacy and morality are ones of objectification and heterogeneity. Through narrative the phenomenon of subjectivity can be reclaimed, and time can be made more particular in order to open law up to greater particularity, showing how we can be different despite 'all being Greek'. As MacIntyre (2007) states:

I am never able to seek for the good or exercise the virtues only qua individual ... we all approach our own circumstances as bearers of a particular social identity. I am someone's son or daughter, a citizen of this or that city. I belong to this clan, that tribe, this nation. Hence, what is good for me has to be good for someone who inhabits these roles. I inherit from the past of my family, my city, my tribe, my nation a variety of debts, inheritances, expectations and obligations. These constitute the given of my life, my moral starting point. This is, in part, what gives my life its moral particularity. (p. 220)

Narrative impacts personal identity in at least three important ways (Kemp 2002:279-290). It allows for the individual to see himself as a coherent temporal identity, as a person and as an acting agent. Secondly, through expressing ideals of rejecting evil and striving towards the good life, narrative allows us to build an ethical identity. Thirdly, it lays the foundation for social societies with ideals and ideologies that are always in tension. Although ethical laws such as the categorical imperative are non-narrative, the application thereof in service of the good life is necessarily narrative (Kemp 2002:279-290).

Ricoeur asserts that the self can be conceived of in two ways. The idem is the unchanging aspects of the self, whilst ipse carries no notion of fixedness, but rather the changing self within time (Rasmussen 2002:59).

Individual selves have both physical and mental particularities assigned to it, and these particularities have some form of narrative continuation, the 'sameness' of idem. These particularities can of course be described as they appear in a third person, but they can also be assigned to and by the first person, as Ricoeur describes the distinction, as something observed and something felt. This poses a problem: if the self can ascribe particularities to itself in constituting itself, how can we defend the self from being constituted through the same act of description by others (Rasmussen 2002:57-70)? Through contemplation it becomes clear that the self has a special relationship with its own speech. Speech itself is an individual act in the world of actions. This contrasts sharply with Luhmann's claim that 'human beings do not and cannot communicate - only communication can' (Moeller 2006:6). In narrative time we find communication reclaimed by the agents of that communication. Identity is formed through the act of communicating instead of humans being subservient to a communicative system. From this perspective, communication takes on a much more important role and is opened up for judgement on norms outside of the given system in which it functions, namely norms such as justice.

One mistake that Ricoeur feels is made too often - with clear implications for law - is the rigid separation between 'action' and 'motivation' (Pellauer 2007:95). When the what of an action is apparent, the question as to why often follows. As an alternative a more phenomenological understanding of action would allow for a more nuanced understanding where the reasons for motivation, cause and effect, are more intertwined to the point where they can even be teleologically understood (Pellauer 2007:95). Both motivations and causes can be ascribed to the same agent or self. When such an enquiry has been made, an act is imputed to the self, a process that repeats itself daily in courts. It needs to be remembered, however, that the agent or self to whom we are imputing acts and effects also has a history and a special relationship with time. The temporal existence of the self is essential for understanding personal identity; time and history are essential when making ethical judgements of individuals and their actions.

It is at this level that the distinction between die static ipse identity and the fluctuating idem identity becomes important. There is of course a permanence that applies to selfhood. Character, or the 'set of distinctive marks which permit the re-identification of a human individual as being the same', is proof of this (Ricoeur 1993:119). Between these two poles - between identity and sameness - is where Ricoeur's emphasis of narrative identity lies. Since narrative can never be ethically neutral, this also becomes the first terrain in which ethical judgements can be made. Narrative turns the ipse into a dynamic identity over time. Not only do agents find themselves in plots, but are in fact plots in themselves. Individuals are constituted of the same dialectic that occurs in the employment of action (Pellauer 2007:101).

In such a narrative identity, does the agent have to remain the same self over a long temporal stretch? The fact that another can gain or suffer under the actions of an agent makes this question important, if for no other reason than an ethical one (Pellauer 2007:102). It is exactly because of this that an agent or another can become an object of moral imputation or description.

Ricoeur imagines three tiers in what he calls his 'little ethics', moving from a teleological level to a deontological one, and eventually a practical level (Pellauer 2007:102). The first stage he calls 'ethics', the aim of the good life with and for others with just institutions. This intention needs to be unfolded 
through concrete acts, and eventually different acts being drawn together into a narrative whole. Narrative performs the function of imparting identity. This narrative identity requires the other to realise itself, an obvious manifestation being that of the self's duty toward others. This other does not exclude institutions such as law. For institutions to be just they have to act further than mere procedural formulations and utilitarian considerations. This of course is unfortunately exactly the manner in which the law operates.

Ethical intentions and moral obligations eventually need to be applied to practical problems. As Ricoeur (1993) writes:

This passage from general maxims of action to moral judgment in situation requires, in our opinion, simply the reawakening of the resources of singularity inherent in the aim of the true life. (p. 240)

This stage may (and probably will) involve conflict and as he notes, tragedy. This may lead to disillusionment or to catharsis and self-knowledge. Either way it contributes to recognition of the self. Again this lies in contrast with Luhmann's stance on the dividing effects of ethics. Whilst both admit that conflict is often inevitable, Luhmann wants to shy away from its destructive effects whilst Ricoeur sees it as necessary for the establishment of even clearer identity.

Beyond the rules of procedure a vast amount of options on the distribution of the good are available, creating the politics of conflict (Ricoeur 1993:106). The key is however not to preserve coherence in the way that legal reasoning does but to construct it. An ethics of communication needs to be established in order to revise what we understand as ethical argument under current autopoietic thinking.

It is in Ricoeur's description of political identity that the false dilemma posed by the question 'what am I if we are all Greeks?' is illuminated. Public and political agendas fortify social cohesion needed for public projects, which again is needed for social progress (Kemp 2002:279-290). Yet to accept a political identity is to accept a set of normative claims that one has not determined for oneself (Dauenhauer 1997:129139). Part of this is the delineation of political boundaries, of an 'us' and 'them'. The problem with these issues is that they either ask for individual autonomy to be discarded or for a denouncement of the common humanity that individuals share (Dauenhauer 1997:129-139).

Narrative does provide us with a compromise by bridging the aporia between the idem and ipse identities. It allows us to understand ourselves as distinct individuals within human communities. Narrative also allows for the initiating and following through of (political) projects. These narratives allow for evaluation, but can also be subject to evaluation (Dauenhauer 1997:131). These evaluations then give rise to 'considered convictions' that influence further thoughts and actions (Dauenhauer 1997:131). However, these convictions and narratives are imperfect and partial. There is discrimination on what is included and excluded and the weight of emphasis given to a particular aspect. It is for this reason that such convictions can always be the subject of further reflection and criticism. Dramatically changing one's convictions is a reaffirmation of the gap between idem and ipse identities (Dauenhauer 1997:131).

The impact of the narrative political society on the idem identity of the individual, can be seen in the two opposite events of an individual's life, namely their birth and death (Dauenhauer 1997:133). When an individual is born (or thrown in the words of Heidegger), the individual is an agent capable of action, of either taking up the political society's projects or undermining them. Society thus walks the tightrope act of trying to educate the individual to be supportive of its projects (and feel obligated to perpetuate them) without disregarding individualism and initiative. Death marks the end of the being's projects, including the Ricoeurian project of self-maintenance (Dauenhauer 1997:133).

It is clear that the above mentioned spheres of identity are in conflict with one another, the individualism of the one against the collectivism of the other. Already in this conflict there is room for ethical evaluation. Narrative never allows for any situation to be ethically neutral. At this point a person - normally the agent who claims the narrative - needs to make an ethical decision. For Ricoeur, this is also the point where narrative identity needs to give way to a non-narrative component in order for the agent to be an acting subject (Kemp 2002:279-290).

Does this imply that there are a priori non-narrative ethical claims that are superimposed onto narrative (Kemp 2002:279290)? Or does it mean that once a narrative ends there are ethical responsibilities that need to be fulfilled? As has been indicated, identity consists of both idem and ipse elements, selfhood and sameness. This sameness is maintained by imagining and striving towards the good life. Of course, this good life is imagined in a narrative form. It is also through narrative form that ethical experience and instruction is related. Ethics exist because of the 'refiguration of action by the narrative' (Ricoeur 1993:164).

Narrative time thus opens identity to a realm where it needs to always re-evaluate and reaffirm itself. This is because identity is important and has a role to play in the functioning of society. The temporal duration that is inherent in narrative allows for ethical judgements to be made of what individuals do. Law, by disengaging from time, strips identity of this ethical character and thus denies its own responsibility toward justice. Understanding humans as narrative creatures shows sensitivity to our temporal existence and demands that law treats its subjects justly.

\section{Agency}

According to Luhmann, all social and communicative action takes place within an autopoietic system. Therefore a human agent cannot speak of 'acting'. All such actions take place within the system and by the system, whilst human agents find themselves in the environment of said system. As we 
have seen, human action has been typified as the result of communication, and not vice versa (Currie 2010:12). The result is a total placement of psychic individuality outside of the sphere of social systems.

The separation of a system and its environment has an effect on causality, the boundary bisecting causal connections. That is why it is important to understand how causality is spread over system and environment. Systems can produce some but not all - causes necessary for effects under the control of said system. This selection of 'some but not all' implies decision making, and thus retention. Over time a collection of beneficial and productive causes accrue and as it grows, gain more influence over its environment as well as its own evolution and self-preservation. In this manner causality becomes an organisation of self-reference, distributing causation across the system and its environment.

Systems have a particular way of dealing with information. Information can be defined as either an internal or external event that enters the system and makes selections regarding the state of a system. This happens when a difference comes into contact with the self-referential operations. Once this happens certain causal future outcomes come into being through operation (or even disoperation) of the system. This branching out of possible futures lends self-determination to the system. These different ways of conducting and affecting itself can be stored and recalled. These 'branches' enter the system when difference occurs, making information possible without affecting the course this information of difference will run. After these possibilities have manifested a system can recall it and use its own past as its own causal basis, removing it from the causation of the environment without fixing or predetermining its own internal causality. Again this is what grants it self-determinacy and immunity from the causal laws of its environment. Such demands are merely internalised as difference from which point itself can decide what the causal implications are. In this manner improbable (or even improper) futures and effects can be logically explained, or as Luhmann says 'they presuppose themselves as the production of their self-production' (see Moeller 2006:41)

The implication is that the true weight and nuanced character of human action is reduced in complexity, dragged across the boundary into the legal system, and described in ways that do not reflect it accurately. Human action is removed from the hands of its agents and becomes a legal system; with its motivations and goals being replaced by those that the system designates it with. It is difficult to imagine how justice can be done if actions can only be expressed legally and not in their true narrative context. Law is not concerned with truly engaging with time which necessarily makes a just engagement with action or causation impossible. Whilst this can still lead to just results in some (or even many) cases, they cannot be because of convincing ethical or reasoning or motivation. They will remain hollow symbols without the content of justice.
Autopoietic legal systems strip action and causation of complexity the moment they cross the boundary from environment into law. Very complex human motivation and behaviour is decontextualised and simply given legal designations that imply and lead to a preset of legal outcomes. Again, part of the problem is that law seems unwilling to put action and causality in a sufficiently broad temporal frame, stripping human action from much of its complexity and nuance.

An important element for understanding causality in narrative time is the idea of mimesis. Mimesis in this sense means 'imitation' (Dowling 2011:2). Like the famous saying 'art imitates life', narrative relies on the imitation of mimesis. For Ricoeur there are three levels of mimesis, which he calls Mimesis ${ }_{1}$, Mimesis $_{2}$ and Mimesis ${ }_{3}$ (Dowling 2011:3).

All of communication and society is governed by signs and symbols. To make sense of these signs, we need a structure of understanding and experience that is somehow prenarrative and 'pre-understanding', the level of Mimesis (Dowling 2011:3). Action is after all not only movement, but also intrinsically linked with motives and goals. This prenarrative knowledge confers a degree of readability on to human action and provides the context in which it can be interpreted. Law forms part of this cultural and symbolic order. Mimesis ${ }_{1}$ grants us the ability to read and understand the rituals of law, and the beliefs and values that it exercises.

Narrative structures human actions so that it can have causality. Without narrative human actions would be no more than 'one thing after another'. In other words, narrative lends causality to human action through 'emplotment' (Dowling 2011:7). This emplotment can only occur when it is grounded within Mimesis ${ }_{1}^{\text {'s }}$ pre-understanding of the world of signs and actions.

The next level of mimesis is that which gives us the logic of narrative causality. Ricoeur sees narrative causality less linear, as a spatial and temporal structure: a 'chain of causal implications that must be traversed in time' (Dowling 2011:8). Action only makes sense within its spatio-temporal context - only then can different actions be seen in unison and teleologically inevitable. Ricoeur insists that human action has to be seen in totumsimul, as a timeless whole, being told both forwards and backwards. Even when the outcome is unclear in the middle of a plot, it is accepted that there is an ending that is understandable in the context of the whole. In other words, when looking at a plot 'backwards' from an ex post facto position, it is clear that it always formed part of coherent union (Dowling 2011:9).

This creates a double temporality, namely the forward temporality of the events as they happen, as well as the backward temporality of reflection upon the past. This coherent union created by the double temporality creates the possibility of moral and ethical evaluation that is impossible in the 'sequence of now' of the presentism found in autopoietic legal systems thinking. 
Action, however, cannot exist in a vacuum of context. Mimesis $_{3}$ represents this 're-figuration' (Dowling 2011:14) when the reality of the narrative time in question is reconciled with the prejudice of the observer on its route to total comprehension. An encounter with narrative is necessarily a struggle between two different spheres of reality, that of the narrative itself and that of the person judging it. The narrative becomes a formal projection within the reality of the person encountering it (Dowling 2011:14). The process of following a narrative at this level is however, unavoidably a temporal one itself. Narrative would serve no purpose if its judge did not share the imperfect knowledge of the actors and the entire exercise loses its point if the judge had complete clarification of events from the outset. That is why Mimesis $_{3}$ is a process of re-figuration: the cognitive process from 'not-knowing' to clarity exposes a new reality that was not apparent at first. ${ }^{2}$

This movement from Mimesis ${ }_{1}$ through to Mimesis $_{3}$ - from pre-narrative knowledge of communities to the individual change brought about by narrative experience - is an important one. It is true that narrative abstracts human action to some level, but ultimately it is human action itself that is abstracted in a way that is necessary for human reflection on the past. An autopoietic legal system is in itself already abstract, translating human action into a 'machine code.' In other words, it is a level of abstraction removed from that of narrative.

\section{Redeeming legal identity and agency}

For Kant, time is an essential part of the human cogito: I think, thus I am active. I exist and my existence can only be defined as the existence of the passive I in time. Time becomes a component of the cogito, a form of inner tuition, whereas space becomes outer tuition. This makes space, time and cogito interrelated (Nousiainen 1995:29). There are therefore two time structures: a subjective, active and ex ante time, and an objective, passive, ex post time. This is problematic for law, since law produces only a 'subject structure' that keeps apart the subject in its active and passive formulations. According to Kant, human beings are intelligible in action, and sensible in effects. The subject is intelligible making it a cause of action. Since time is not a condition of things in themselves, the acting subject does not fall under any of the conditions of time. This means that the intelligible subject has to be free from all influences of sensibility. In jurisprudence this 'anatomy of pure reason' has been developed into the doctrine of causality, imparting agency on legal subjects, and allowing law to judge them.

Man has the ability to imagine his present as the object of a future memory, also called 'prolepsis'. The ultimate reason for prolepsis is for consciousness to create a temporal selfdistance from where it can look back on its current present from the future. In this way the future can act as a causal agent for the present. When a sportsperson imagines a future where he or she wins an Olympic medal, it spurs him or her on to train harder in the present. ${ }^{3}$ Is this some sort of reversed time or causation?

Again we have to look at Derrida's notion of supplementarity, where instead of adding on to an event, the temporal structure in fact produces it (Currie 2010:7). The word 'produces' is implicated in causality. Can a later event really cause an earlier one? The answer is that the second event's posteriority is imagined and not real. The anticipation of the later event in fact does cause the primary event. In the language of law this has been labelled as 'intention'.

This break created between internal and external time opens itself up to deconstruction. Ricoeur recognises this, and again believes that narrative is the structure best suited toward exploring these Husserlian protentions and real futures (to the agreement of Derrida's remembering of the future; Currie 2010:76). Whilst science is restricted to the noumenology of external time, philosophy is restricted to the phenomenology of internal time. The fact that consciousness cannot remove itself from the object world is the reason why supplementarity has to think about phenomenological and noumenological time together. It is not argued here that external time can go backwards and actually produces events in the past. Protentions are merely projected futures. However, internal time is the only way consciousness can experience time, and therefore these ideas have to carry some weight.

Derrida's supplementarity is based in phenomenology. In creating his concept of 'différence' he borrows Husserl's structure of the present as a thatched structure of protentions and retentions and that the present is always divided by the past and the future. In this manner the present is similar to a sign in the sense that it is constituted by its relationship with other signs together with which it forms a system (Currie 2010:75). The present is itself nothing but a crossed structure of the past and the future.

It remains true that these theories do not offer a contradiction to the one-directionality of time. Whilst there is an aporia between internal and external time, the direction of each is not in contestation. If we agree with Kant that noumena (or things in themselves) are unavailable to consciousness, the real nature of time is irrelevant to us since we can only deal with the phenomenon. The anachronicity of internal time is only understood in contrast to external time (Currie 2010:75).

Kant also saw the birth of Newtonian causality as the death of mental and teleological causality, stemming from an archaic folk psychology. For Ricoeur the kind of causality rooted in action stands in the same relation to cultural reality as material causality does to the physical universe (Dowling 2011:54). Whilst material causality derives its authority from noumenological generalisations, the causality of culture draws its authority from narrative which itself is rooted in the pre-narrative structure of real action. Treating human action in relation to historical truths is a scientific history, and not philosophically sound (Dowling 2011:54).

3.Another example is when a person unwittingly sits on a drawing pin. His first reaction is 'pain', and only on closer investigation discovers the pin. If it were not for the pain, the pin would never have been discovered, and in a mental process the the pain, the pin would never have been discovered, and in a mental process the
order is reversed to create a causal link. Yet the truth remains that the pain was the production of the cause. 
Humans are born into a world that is already filled with meaning, moving in cultures that are complex systems of values and beliefs. Within these cultures complex structures such as politics, religion and indeed law is formed. These structures or systems become autonomous powers that can mould individual will and action, in what Dowling (2011:54) calls an 'objectification of life.'

When humans try to understand the circumstances and causal links of a set of facts, we reconstruct our own experiences within the temporal place and circumstances of the given facts. The problem with this is that motivation and intention of those judged cannot be transposed (Dowling 2011:56). Law attempts to circumvent this through speculative deduction, imparting the prejudices and experiences of the legal officer onto the characters in the facts. Ricoeur critiques the introduction of physical causality into human volition. Law confuses if $X$ then $Y$ with $X$ caused $Y$. It also often neglects 'non-individual social forces' such, for example, as economy and culture (Dowling 2011:54). Human action does not only have a causal motivation but a teleological one as well. The reductive and 'small' actions with which law busies itself need to be placed in a larger temporality for teleological understanding.

Legal interpretation reduces concrete situations into abstract legal oppositions (Nousiainen 1995:26). The autopoietic translation of information disregards the narrative of an event and turns it into competing abstract rule sets. Judgements in themselves have an a posteriori viewpoint, and rarely attempt to overcome the temporal distance to see the facts from the original a priori view. Through the employment of narrative time law has no choice but to engage ethically and justly with time action and causation. Whilst boundary formation allows law to ignore the full complexity of human identity and action, narrative time makes it impossible to deal with them any other way. Narrative time could open legal boundaries to the complexity of its environment instead of its own artificial complexity.

\section{Conclusion}

Narrative holds answers that law does not possess. Narrative holds promises of unspoken knowledge that are non-legal and even non-philosophical, something more subtle than the crude forms of empirical knowledge. These accidental insights can inform us of ourselves and the Other.

Narrative identity can be employed as a possible solution for the shortcomings of legal systems theory engagement with the individual and his actions. They are shown to be filled with an ethical dimension that law has seemed to ignore. It imparts ethical particularity of the individual in his personal and political identity, separating it from the legal heterogeneity that we encounter. Through the changing element of identity distance comes into being that allows the unchanging self to be judged, which leads to self-knowledge and ethical development.

Just as the nuanced and ethical dimension of identity comes to the fore, so does narrative redeem human action. Through mimesis narrative time gives us a structure for the preunderstanding of human action. The environment is filled with meaning and symbolism that frame our actions. Actions have real meaning beyond the mere physical events typified by autopoiesis. It allows for the teleological understanding of action, and even admits that the interpreter of action (such as a judge) adds an additional layer of meaning onto it.

Narrative is one mode of not allowing law to shirk its responsibility to engage with justice. If law can be ridden of its self-interest, the mechanism it has developed to protect itself from norms of justice can be implemented alongside legal norms, giving rise to better law. When law's boundaries, drawn by autopoiesis, are opened, it will allow for a much more complex vision of humans and their actions to become available to it. This complexity can manifest itself in narrative. When faced with narrative identity, we will be unable to ignore the ethical dimension that narrative intrinsically demands. When this self-consciousness is breached, nothing stands in the way of law to appeal to norms of justice, and hopefully experience its own self-distance necessary to see itself and others in a new light 'to emerge from ourselves, to know what another person sees of a universe which is not the same as our own' (Dowling 2011:52).

\section{Acknowledgements Competing interests}

The author declares that he has no financial or personal relationship(s) which may have inappropriately influenced him in writing this article.

\section{References}

Currie, M., 2010, About time: Narrative, fiction and the philosophy of time, Edinburgh University Press, Edinburgh.

Dauenhauer, B.P., 1997, 'Ricoeur and political identity', in M. Joy (ed.), Paul Ricoeur and narrative, pp. 129-139, University of Calgary Press, Calgary.

Dowling, W.C., 2011, Ricoeur on time and narrative: An introduction to temps etrécit University of Notre Dame, Notre Dame, IN.

Kemp, P., 2002, 'Narrative ethics and moral law in Ricoeur', in J. Wall, W. Schweicker \& W.D. Hall (eds.), Paul Ricoeur in contemporary moral thought, pp. 279-290, Routledge, New York.

Luhmann, N., 1995, Social systems, transl. J. Bednarz, Stanford University Press, Stanford, CA.

Luhmann, N., 2008, Law as a social system, Oxford University Press, Oxford.

Maclntyre, A., 2007, After virtue, University of Notre Dame Press, Notre Dame, IN.

Moeller, H. G., 2006, Luhmann explained: From souls to systems, Open Court, Chicago/ La Salle, IL.

Nousiainen, K., 1995, 'Time of law - time of experience', in J. Bjarup \& M. Blegvad (eds.), Time, law and society, pp. 23-40, Franz Steiner Verlag, Stuttgart.

Pellauer, D., 2007, Ricoeur for the perplexed, Continuum, London.

Kant, I., 1993, Critique of pure reason: A revised and expanded translation based on Meiklejohn, V. Politis (ed.), Orion Publishing Group, London.

Rasmussen, D., 2002, 'Rethinking subjectivity: Narrative identity and the self', in R.A. Cohen \& J.L. Marsh (eds.), Ricoeur as another: The ethics of subjectivity, pp. $57-$ 70, State University of New York Press, New York.

Ricoeur, P., 1983, Time and Narrative, vol. 1, transl. K. McLaughlin \& D. Pellauer, University of Chicago Press, Chicago, IL.

Ricoeur, P, 1984, Time and Narrative, vol. 2, transl. K. McLaughlin \& D. Pellauer, University of Chicago Press, Chicago, IL. http://dx.doi.org/10.7208/ chicago/9780226713519.001.0001

Ricoeur, P., 1988, Time and narrative, vol. 3, transl. K. McLaughlin \& D. Pellauer, University of Chicago Press, Chicago, IL. http://dx.doi.org/10.7208/ chicago/9780226713533.001.0001

Ricoeur, P, 1992, Oneself as another, transl. K. Blamey, University of Chicago Press, Chicago, IL. PMid:8110526 